\title{
Sharing experience from Chinese General Practitioners to International colleagues on how to tackle COVID-19
}

\author{
Shanzhu Zhu ${ }^{1}$, Donald $\mathrm{Li}^{2^{*}}$ \\ ${ }^{1}$ Cross-Straits Medicine Exchange Association - Committee of General Practice, China \\ ${ }^{2}$ Hong Kong GP, President of World Organization of Family Doctors (WONCA) \\ Corresponding Author* \\ Donald Li: Hong Kong GP, President of World Organization of Family Doctors (WONCA) \\ E-mail: dr2318@hotmail.com
}

China was the first country where the novel coronavirus appeared. General Practitioners (GPs) in China are at the forefront of tackling the spread of the virus. While the health sector in China has been under scrutiny globally, many articles have been disseminated within the country about the response. GPs in China are keen to share their experiences with GP colleagues, as other countries go through similar experiences. The hope is that by sharing our experiences, our international colleagues can benefit from what worked well and what went less well.

Coronavirus started spreading from Wuhan in Hubei Province in late 2019. As in many parts of China, Wuhan is a hospital-oriented health service, as the family medicine system is not yet fully implemented. The surge of patients to hospitals quickly overwhelmed the health system in Wuhan and surrounding towns and cities, as patients sought testing and treatment, and in the process helped to spread the virus more quickly. The experience has put the spotlight on the ineffectiveness of hospitals as the first port of call for this and other types of virus.

GPs working in the community are engaged in diagnosing and treating patients, educating the public and guiding the community in the fight against the outbreak. The main challenges for all health care providers, but for GPs in particular, are the overwhelming numbers of patients, the adverse working conditions - including exposure to infectious risks, the uncertainties and unknowns about the trajectory of the disease, and coping with fears and panic among the population. For GPs, the challenges do not end there: the continuity of care and treating the whole person rather than the single disease are essential inputs by GPs to lead the community to the path of recovery.

World Health Organisation (WHO) led a Joint Mission to China in mid-February 2020 where they commended the three-phase response established. As detailed in the WHO report, Phase 1 of China's response was to prevent cases from spreading from Wuhan to other areas; to control the source of the infection, block transmission and prevent further spread. Phase 2 was to reduce the epidemic and slow the increases in cases, with all patients treated and close contacts isolated. Phase 3 focuses on reducing clusters of cases, thoroughly controlling the epidemic and striking a balance between epidemic prevention and control, sustainable social and economic development ${ }^{1 .}$

Community engagement is the first line of defence in the battle against infectious diseases. GPs are both gatekeepers and health promotors by empowering the community to build a firewall against the deadly virus. GPs are engaged in each of the three phases of response to the disease. For example, they help block the viral transmission in Phase 1 by monitoring people at designated checkpoints; they slow the increase of cases by treating patients and providing medical surveillance in the community in Phase 2. In Phase 3, they take care of the clinical and psychological well-being of patients and extend that to their families, so the whole community can return to normal life, as soon as practical.

There are numerous instances of individual and team responses to the outbreak, many of them reflecting on the efforts of GPs who have developed trust and good communication with their patients. Providing both personal care and online support has helped to alleviate the inevitable anxiety which can quickly take hold in communities.

In 2016, the Chinese State Council issued guidance on the promotion of Family Medicine, with the aim of extending availability of family practice to the entire population by $2020^{2,3}$. This hasn't been fully implemented but is well under way. As the health system responded to the rapid spread of the coronavirus outbreak, the efforts and professionalism of GPs has been widely acknowledged and reported in the Chinese press. The COVID-19 outbreak has refocussed attention on the 'first in last out' role of the GPs and has reinforced the need for widespread availability of qualified GPs across the country. Through remarkable individual and team efforts, displaying truly

\footnotetext{
${ }^{1}$ Report of the WHO-China Joint Mission on Coronavirus Disease 2019 (COVID-19), WHO official website https://www.who.int/docs/default-source/coronaviruse/who-china-joint-mission-on-covid-19-finalreport.pdf

${ }^{2}$ Li L, Zhong C, Mei J, et al Effect of family practice contract services on the quality of primary care in Guangzhou, China: a cross-sectional study using PCAT-AE. BMJ Open 2018;8:e021317. doi: 10.1136/bmjopen-2017-021317 https://bmjopen.bmj.com/content/8/11/e021317

3 "Family doctors the future of China's healthcare system", China Daily, 26 February 2016, https:/www.chinadaily.com.cn/china/2016-02/26/ content_23657040.htm
} 
professional general practice, the role of family medicine in the Chinese health sector is now well recognised.

Acknowledgements for help in preparing the paper to: Hao $\mathrm{Wu}$, Director, Fangzhuang Community Health Service Center, Fengtai District, Capital Medical University, Beijing, China; Qiao Jianrong, WHO Coordinator, Health Systems and Health Security, Office of WHO Representative in China

\section{REFERENCES}

1. Report of the WHO-China Joint Mission on Coronavirus Disease 2019 (COVID-19), WHO official website https://www.who.int/docs/ default-source/coronaviruse/who-china-joint-mission-on-covid-19final-report.pdf
2. Li L, Zhong C, Mei J, et al Effect of family practice contract services on the quality of primary care in Guangzhou, China: a cross-sectional study using PCAT-AE. BMJ Open 2018;8:e021317. doi: 10.1136/ bmjopen-2017-021317 $\quad \underline{\text { https://bmjopen.bmj.com/content/8/11/ }}$ $\underline{\mathrm{e} 021317}$

3. "Family doctors the future of China's healthcare system", China Daily, 26 February 2016, https://www.chinadaily.com.cn/ china/2016-02/26/content_23657040.htm 